\title{
Moral experiences of humanitarian health professionals caring for patients who are dying or likely to die in a humanitarian crisis
}

Matthew Hunt ${ }^{1,2^{*}}$ (D), Ani Chénier ${ }^{3}$, Kevin Bezanson ${ }^{4}$, Elysée Nouvet ${ }^{5}$, Carrie Bernard ${ }^{6,7}$, Sonya de Laat ${ }^{3}$, Gautham Krishnaraj ${ }^{3}$ and Lisa Schwartz ${ }^{8}$

\begin{abstract}
Wars, disasters, and epidemics affect millions of individuals every year. International non-governmental organizations respond to many of these crises and provide healthcare in settings ranging from a field hospital deployed after an earthquake, to a health clinic in a longstanding refugee camp, to a treatment center during an infectious disease outbreak. The primary focus of these activities is to save lives. However, inevitably, many patients cannot be saved. We undertook an interpretive description study to investigate humanitarian policy-maker and care providers' experiences and perceptions of palliative care during humanitarian crises. In this paper, we report on interviews with 23 health professionals, 11 of whom also had experience as policy-makers within a humanitarian organization. We use the concept of moral experience as an analytic lens: participants' experiences of values that they held to be important being realized or thwarted as they responded to the needs of patients who were dying or likely to die.

We identified five themes related to participants' moral experiences, all of which relate to values of compassion in the provision of care, and justice in accessing it. (1) Participants described intervening to ease the suffering of dying patients as an inherent aspect of humanitarianism and their duty as health professionals. (2) Participants also expressed that upholding dignity was of critical importance, stemming from a recognition of shared humanity and as an act of respect. (3) Since humanitarian action is provided in situations of scarcity, prioritization is inescapable. Acknowledging the primacy of curative care in emergencies, participants also emphasized the importance of ensuring that care for the dying was attended to, including during triage. (4) Participants reported working within and pushing against systemic constraints such as legal or logistical barriers to opioids, lack of guidelines, and conflicting views with colleagues. (5) Given the stakes involved, participants felt a heavy weight of responsibility and described their challenges in carrying it. These findings illuminate experiences responding to patients who are dying or likely to die, and how these connect with the values of humanitarian health professionals, sometimes resulting in dissonance between values and actions. They also point to the need to make more space for palliative, alongside curative, approaches to care in situations of humanitarian crises, ideally by further integrating them.
\end{abstract}

Keywords: Disaster, End-of-life, Epidemic, Ethics, Humanitarian crisis, Moral experience, Non-governmental organizations, Palliative care, Relief work, Values, War

\footnotetext{
* Correspondence: matthew.hunt@mcgill.ca

'School of Physical and Occupational Therapy, McGill University, 845

Sherbrooke Street West, Montreal, Quebec, Canada

${ }^{2}$ Centre for Interdisciplinary Research on Rehabilitation, Montreal, Quebec,

Canada

Full list of author information is available at the end of the article
} 


\section{Introduction}

Humanitarian healthcare aims to save and safeguard the lives of people caught up in situations of crisis. This is enacted in diverse settings: international non-governmental organizations (NGOs) implement vaccination and feeding programs, set up treatment centers during outbreaks of infectious diseases such as cholera and Ebola, provide primary care in refugee camps, and establish field hospitals to deliver surgical care during wars and following natural disasters, amongst many other actions. Despite the best intentions and dedicated care of humanitarians, many patients will die due to injury or incurable disease. This is an inescapable reality, especially given the precarity and resource scarcity that characterize humanitarian crises. The overriding imperative of saving lives in humanitarian healthcare, however, has often left limited room for addressing suffering and dignity, especially for individuals who are dying, in humanitarian settings (Powell et al. 2017). There has also been a lack of guidance and support related to caring for dying patients during humanitarian crisis (Nouvet et al. 2018), a situation which may increase uncertainty and lead to moral distress.

In the past few years, increased attention has been directed toward palliative care provision by humanitarian health professionals. The World Health Organization (WHO) defines palliative care as "an approach that improves the quality of life of patients (adults and children) and their families who are facing problems associated with life-threatening illness. It prevents and relieves suffering through the early identification, correct assessment and treatment of pain and other problems, whether physical, psychosocial or spiritual" (WHO 2018). Commentators have argued for the importance of palliative care provision in situations of war, disaster, and epidemic (Marston et al. 2015; Smith and Aloudat 2017), with Powell et al. arguing that it should be considered "an integral component of relief strategies" (2017: 1498). Some NGOs have established policies to support their field teams in providing care for patients who are not expected to survive, such as the International Committee of the Red Cross's triage guidelines which identify minimum care standards for these patients (Giannou and Baldan 2009). Broader efforts that cross the humanitarian field are also underway, including an initiative to introduce a new chapter in the Sphere Handbook: Humanitarian Charter and Minimum Standards in Humanitarian Response addressing "relief of

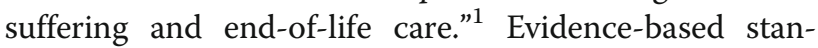
dards for supportive care in Ebola Treatment Centers have also been developed and include recommendations for pain control and addressing psychological distress (Lamontagne et al. 2018).

These initiatives have the potential to further foreground the need for palliative care in humanitarian settings and establish guidance to help orient practice. There remains, however, little information about palliative care interventions carried out as part of the humanitarian response to crises (Schneider et al. 2017), including experiences of patients, families, and care providers. With the goal of better understanding opportunities, obstacles, and experiences of palliative care provision in humanitarian crises, we have undertaken a multi-stage research project that includes a survey, interviews with humanitarian health professionals and policy-makers, and in-depth case studies, including interviews with patients, families, and health professionals in Rwanda, Jordan, and Guinée (Humanitarian Health Ethics Research Group 2018). In this paper, we focus on experiences of providers of care and report on interviews we conducted with 23 health professionals, 11 of whom also had experience as policy-makers within humanitarian NGOs. Our analysis focuses on their moral experiences, that is situations in which they experienced values they held to be important as being realized or thwarted (Hunt and Carnevale 2011) as they responded to the needs of patients who were dying or likely to die in a humanitarian crisis.

\section{Methods}

This inquiry was guided by interpretive description methodology (Thorne 2016) and was undertaken within a constructivist paradigm in which human experience is understood as subjective, local, socially and experientially based, and culturally and historically specific (Lincoln et al. 2011). Interpretive description aims to develop a "coherent conceptual description that taps thematic patterns and commonalities believed to characterize the phenomenon that is being studied and also accounts for the inevitable individual variations within them" (Thorne et al. 2004:7).

Here, we report on our analysis of the interviews answering the following question: "What are the moral experiences of humanitarian health professionals as they respond to the needs of individuals who are dying or likely to die during a humanitarian crisis?" This analysis is guided by the following understanding of moral experience: “Moral experience encompasses a person's sense that values that he or she deems important are being realized or thwarted in everyday life. This includes a person's interpretations of a lived encounter, or a set of lived encounters, that fall on spectrums of right-wrong, good-bad, or just-unjust" (Hunt and Carnevale 2011:659). Thus, inquiry into moral experience aims to illuminate "the local processes (collective, interpersonal, subjective) that realize (enact) values in ordinary living" (Kleinman 1999:71).

\section{Ethics}

This study was reviewed and approved by the Hamilton Integrated Research Ethics Board at McMaster University, 
and the McGill Faculty of Medicine's Institutional Review Board. All participants provided written informed consent to participate in the study.

\section{Recruitment}

We recruited participants using four approaches. First, we distributed information about the study on social media (via our research group's Twitter and Facebook accounts). Second, we shared information within our professional networks which resulted in the recruitment of 11 participants. Third, at the end of the survey that was conducted by our research team as part of the broader project (see Elrha 2017), we invited survey respondents to indicate their interest in also participating in an interview. Nine participants were recruited through the survey. Finally, we recruited three participants using snowball sampling, asking interviewees to suggest others who might be interested and eligible to participate in the study. Throughout this process, we attempted to recruit a diverse group of participants, including men and women, and individuals affiliated with different organizations, coming from different regions of the world, and with experience working in different humanitarian settings and in different capacities.

\section{Participants}

This paper reports on the analysis of interviews with 23 health professionals (16 physicians, 6 nurses, and one physical therapist), 11 of whom had also worked as policy-makers with a humanitarian organization. In this component of the study, we had also interviewed a non-clinician policy-maker but that interview is not included in the analysis presented here due to our focus on experiences of care provision. The 23 participants were affiliated with 18 different organizations and included 11 men and 12 women. Most of the participants had worked with larger international organizations based in Europe or North America. Our purposive sampling was limited in that participants included more physicians (16) than other health professionals (7) and more individuals from high- (19) than low- or middle-income countries (LMICs) (4).

\section{Interviews}

Interviews were conducted between November 2016 and May 2017, in English or French according to the preference of the participant, and followed an interview guide. We created two versions of the interview guide (one for participants who had experience only as clinicians, and one for participants who also had experience as a policy-maker), and each was refined based on feedback from experienced humanitarian health professionals and policy-makers, and persons with expertise in palliative care. All interviews were conducted by Skype or telephone due to the geographic dispersion of the participants. Interviews ranged from 49 to $92 \mathrm{~min}$ in duration (average $65 \mathrm{~min}$ ).

\section{Analysis}

We initiated the analysis of the interviews as transcripts became available. Inductive coding was done by two team members and organized using NVivo software. There were separate coders for the policy-maker (GK) and health professional (AC) interviews. A team member $(\mathrm{MH})$ independently coded sections of four transcripts (two for policy-makers and two for health professionals), and three team members $(\mathrm{KB}, \mathrm{CB}$ and $\mathrm{EN})$ independently coded one policy-maker interview. The provisional codebook was refined through discussion with the whole team and through comparison of coded transcripts. An analytic structure related to moral experience was then developed by three team members $(\mathrm{MH}, \mathrm{KB}$, and $\mathrm{AC})$ by repeated and close reading of the transcripts, use of visual matrices and concept maps, and discussion. Once an initial analytic structure was established, a team member $(\mathrm{MH})$ reread all transcripts in light of this emerging analysis to test its consistency and comprehensiveness. The analytic structure was then revised through team discussion.

\section{Results}

Participants described and discussed experiences of palliative care provision and reflected on its place in humanitarian response. Using the lens of moral experience, we analyzed narratives of care in which participants experienced values they held to be important as being realized or thwarted. Many values were implicated in these descriptions. They clustered around two underlying commitments: to justice in access to care and compassion in provision of care. Through a process of inductive analysis, we identified five interlinking dimensions of moral experience in relation to caring for patients who were dying or likely to die: acting to ease suffering, upholding dignity, balancing care priorities, working within and resisting systemic constraints, and bearing the weight of responsibility. Two relate to what many understood as imperatives: acting to ease suffering, and upholding and preserving dignity. The other three relate to participants' experience of working to meet these imperatives in the heavily constrained context of humanitarian action: balancing care priorities, working within and resisting systemic constraints, and bearing the weight of responsibility. Distinct yet connected in the underlying commitments to justice and compassion that inspires and informs them, these themes shed light on why and how health professionals engaged in humanitarian crises experience the needs for palliative care provision as morally important, sometimes haunting, experiences. 


\section{Acting to ease suffering}

Our participants viewed acting to ease suffering as an integral component of good care for all patients in humanitarian settings, but especially important for individuals who are dying or likely to die. They also described how, due to various features of wars, disasters, or epidemics, this dimension of care may be neglected or eclipsed by an overwhelming concern for saving lives and stewarding limited resources. As a result, and illustrated in many of the narratives recounted by participants, suffering is too often insufficiently addressed, even more so for people who are dying. Nonetheless, when curative care was unavailable or inappropriate, participants argued that palliative care should be provided and that addressing symptoms and relieving pain was an obligation of humanitarian health professionals, and that not doing so represented an injustice. A physician involved in developing humanitarian palliative care guidelines argued strongly for the importance of alleviating suffering, since "not giving palliative care and pain treatment is exactly like non-assistance to persons in danger or like accepting torture. Because some pains are like torture" (P1). While making these assertions about the importance of alleviating suffering, participants consistently expressed that lifesaving was the primary focus of humanitarian healthcare. Generally, they viewed alleviation of suffering, including for dying patients, as something that was compatible with and complementary to this focus.

Several linked this claim to the mandate of humanitarian action, since "a humanitarian organization...[has] a vocation of caring for the most fragile people in the world" (P4). Given the extreme vulnerability of individuals who are dying, addressing their suffering was described as inherent to the vision of humanitarian action. A physician involved in training and policy-making at an international NGO took a historical perspective, stating that palliation was part of the "DNA" (P10) of humanitarianism as it was central to the founding of the Red Cross movement through the actions of Henri Dunant at the Battle of Solferino in 1859. This aligns with the ideas expressed by participants who emphasized that efforts to alleviate suffering were consistent with, and even amounted to a reclaiming of, humanitarian values. In this sense, these participants felt that humanitarians fall short of their ideals and "miss the mark" (P17) if they do not address suffering, especially of dying patients.

A nurse who had taken part in the humanitarian response after an earthquake and during a civil war described several situations where she sought to address patients' suffering, as well as circumstances when doing so was especially difficult. In her interview, she frequently returned to a situation where active fighting in Central Africa led to her team being "inundated with hundreds of patients" (P19). She asserted that even in circumstances when triaging patients was unavoidable: ...if you don't provide something for pain, and you don't do the little things then - then you're losing a little bit of why you're even there and the whole moral piece to it...the humanitarian piece. Otherwise you're just a bunch of medics running around in the field, trying to...stop the bleeding, but when - if you're gonna be humanitarians, then you have to really look at that human piece...(P19)

Highlighted actions to alleviate suffering included not only providing analgesics but also providing water, putting up a sun shade, and having someone stay with grievously injured patients who were triaged to not receive lifesaving care. Failure to engage in such acts, she felt, would represent humanitarians failing to live up to their values.

Along with mass casualty triage situations, care provision in disease outbreaks was also discussed by many participants as a context where attention to suffering was extremely challenging, yet necessary. While a few stories were related to outbreaks of cholera or other diseases, most were told about the 2014-15 Ebola virus disease outbreak in West Africa to which seven of the participants had responded. In this setting, curative options were not available. A nurse reported, "when I started we had like a $70 \%$ mortality rate, so basically all we were doing was palliative care, I mean we were just making people comfortable... at the end of their lives" (P11).

Several participants described situations in which Ebola patients were dying but infection control measures impeded the alleviation of suffering. These concerns were particularly acute when patients were bleeding and vomiting or had diarrhea. A physician described coming upon an Ebola patient who was imminently dying but who had pulled out her IV and the needle could not be found. While encumbered by their Personal Protective Equipment, she described entering the room with a colleague and:

keeping sort of my buddy safe... and finding the sharp, that's, that's kind of what he did first, you know, finding the hanging needle...I should have tried to at least make her comfortable while we were doing that, and I'm trying to think of the time, how much time passed between us seeing her and her dying and...it was like 20 minutes...so I think even...during that 20 minutes we could've done something. I could have thought to do more or just planned better. (P3)

She expressed regret that she had neither attended to the patient's distress nor been sufficiently attentive to her in the moment of her death.

A physician who had come to West Africa from another African country to participate in the Ebola response 
described a situation when he felt that palliative care had been done especially well:

Yes, there was this boy,...[he] presented to the [Ebola Treatment Center], he had diarrhea and vomiting, and...what we did as palliation, because he died eventually, was IV fluids. I remember that fluids very well, but he kept stooling and vomiting, and at times we had to go in one or two times, and usually we go in shifts, the morning shift, the afternoon and the night shift, so at one point we were going in more frequently because of him. We did a lot of fluid resuscitation. He had a lot of abdominal pain, a lot of abdominal pain, so we tried to use a lot of painkillers. Morphine, Tramadol, tried to use all that. What else did we do? I think psychosocial support...And when we think the patients would have given up on life and think everything is so bad, we would try to send the Psychosocial Team to go talk to them...And I think [that] particular day he sort of deteriorated, and by the end of the day we lost him. There were other instances, but that was the incident that it took me a long time to try to forget it. (P5)

Participants also spoke about the importance of family. Many recognized that during a crisis (an earthquake or an epidemic, for example) patients themselves may have lost family members and be mourning their own losses, and that the loss of family members may compound the feeling of isolation during their own dying process. This was particularly so during the Ebola epidemic when some patients have "already lost you know 10, 15 people in their families. Everybody has lost somebody" (P11). Enabling patients to remain connected with family was presented as a means to alleviate psychological distress. Doing so was described as especially vital and challenging in Ebola Treatment Centers. Such actions included bringing patients to the perimeter fence to interact with family members, or supporting patients in isolation rooms to communicate with family using cellphones or tablets, or by recording video messages (P20). Even in a mass casualty emergency, a participant suggested the importance of creating opportunities for relatives to be together (P14).

Attention to suffering was closely related to concern for upholding the dignity of dying patients, and the two goals were often discussed by participants as intertwined. For example, when replying in the affirmative that providing palliative care should be an obligation of humanitarian organizations in emergency situations, a physician linked suffering, preserving human identity, and dignified death: "if anybody is dying, they should die as a human and not be left to suffer" and "Where there's an emergency and anybody dies, you should die in dignity" (P5). In the following section, we foreground how participants discussed efforts to uphold and preserve human dignity.

\section{Upholding dignity}

Participants consistently emphasized the need for humanitarian health professionals to uphold the dignity of dying patients. The importance of doing so was described as stemming from a recognition of, and response to, dying individuals' humanity and as an act of respect and compassion. In this light, a physician expressed that humanitarian healthcare required "strong people with strong ethics, but also with strong commitment to value and to respect the dignity of people and others" (P10). Another physician expressed that "even if a patient does not have curative solutions", he or she "is still a human being" and requires "decent care for dying" (P14).

Participants described many actions as dignity promoting, one in particular being human touch. A physician reported working in an Ebola Treatment Center where the team placed a "huge focus on sort of attempting to focus on dignity" including ensuring you can "safely touch a person and hold a person and clean a person, you know, when they soil themselves and so forth" (P3). She expressed that in an epidemic, it was critical to see patients as human beings, not just as potential transmitters of disease. Another participant, a nurse, described that even with 50 patients who still needed to be seen by her team, it was important to demonstrate compassion and "hold a child, or to sit and hold someone's hand or stroke their back" (P21). Such actions of human connection were frequently emphasized by participants as they discussed the importance of dignity for dying patients.

A key aspect of respecting the humanity of dying patients-and upholding their dignity-was ensuring that they did not feel abandoned. Referring to a dying patient whom she had witnessed being placed behind a shed because the clinic was overcrowded, a nurse asked, "what is the human thing to do? Putting [dying individuals] behind the shed and forgetting about them is not the answer" (P19). Leaving a fellow human without any care and alone while they were dying was framed as both an injustice and an indignity:

And I think also it provides the patient with the sense of being cared for until the end. That you aren't ... a 'lost cause,' or that you've been ... 'abandoned.' But that your life still matters to the very end, however [much] time you do have, and to live with as much comfort as possible until that time. (P6)

A physician expressed dismay that in a crisis, dying patients were put to the side and did not receive attention and "were already considered dead before they even 
died" (P23). In contrast, several participants described the importance of using "presence well" (P21) and enacting "accompaniment" (P4) for dying patients. Accompaniment also extended to supporting patients' families; a nurse described providing support for the mother of a boy who had a severe spinal cord injury after falling out of a tree as an act of "help[ing] his mother walk through this whole issue" (P19). The value that participants placed on ensuring that dying patients feel accompanied and not abandoned is further illustrated by the following situation. A physician recounted why she had agreed to pray with a patient when the patient asked her to do so. Though describing herself as not religious, she expressed that praying with the patient "basically said I'm with you" (P18). Narratives such as these make visible the link in at least some humanitarian healthcare professionals' minds between responding to palliative care needs with active presence and acknowledging a common humanity.

Dignity was also associated with addressing concerns related to privacy. For example, a nurse described at length why she felt that providing privacy for a dying patient was crucial for her dignity: "that's a huge piece of it too, like not being on display for everybody, so having privacy, I think, when you're talking about what's important in palliative care, the dignity aspect is huge" (P19). She discussed, however, that it was important to consider the possibility of imposing norms of privacy without consulting the patient. Indeed, treating patients with respect as human beings was also linked to allowing patients to voice preferences and make choices. The humanitarian context sometimes makes it hard for practitioners to follow this ideal. Another nurse, reflecting on her experiences of the 2010 Haiti earthquake, noted that with "cross-cultural and language barriers, sometimes the patient's opinions and thoughts just aren't given the time and weight that they ought to be given" (P21).

A majority of participants emphasized the importance of preserving "culturally valued" (P21) and "culturally acceptable" (P7) end of life practices, acknowledging that what constitutes dignity and a dignified death is not the same across the world. This diversity may raise challenges for health professionals, especially for expatriates, including a physician who expressed the importance of caring "for those who may not survive and who also deserve a, whatever you define dignified as, a dignified death" (P6). The cultural dimensions of death and dying-including around dignity-led several participants to suggest that local health professionals were best placed to lead palliative care efforts. They also suggested that local religious leaders were important allies, and several gave examples of working collaboratively with such individuals. An African physician (P5) who had responded to a humanitarian crisis in a neighboring country went further and suggested that palliative care efforts should be community-based with international NGOs' roles limited to providing oversight and support.

Efforts to uphold dignity also extended beyond death and included family bereavement. Participants described the importance of memorials and funeral services, including a physician who explained that she chose to attend a memorial service as a way of honoring patients who had died (P3). Infection control during Ebola presented many challenges in this regard. For example, a nurse reported that while traditional practices of washing the dead body were not allowed due to risks of spreading the virus, they sought to "unzip the body bag for [the family] from a distance so they can see, and having more attention to kind of what the funeral process looked like, and so then we could, at least as much as possible, honor each person" (P21).

From initial contact until after death, actions to uphold the dignity of patients facing death were felt to be critically important, even amidst the inherent complexities of response. Through acts of caring, responding to suffering, upholding privacy, and respecting traditions, participants expressed that the identities and individual worth of each dying person could be realized.

\section{Balancing care priorities}

Efforts aimed at easing suffering and upholding dignity are enacted in a broader humanitarian context, one in which resources are finite and often scarce, and lifesaving remains the primary focus. As noted above, participants accepted this broad understanding of priorities. For example, a participant expressed that in the context of the war in Syria, "those patients with the palliative needs, unfortunately...they start to feel like they are second priority" (P16). A more extreme version of this prioritization was described by a participant in a mass casualty situation following violent clashes in Central Africa: "there's so many that still need your attention that we really have nothing to even offer to those that were not gonna make it" (P19). A nurse stated that:

I mean, obviously in a big disaster, in a big mass casualty event or a really, really, busy complex conflict, the amount of time that people are able to give to palliative patients is going to be limited. And I think that, unfortunately, that's a reasonable decision...(P23)

While acknowledging the need to prioritize lifesaving, several participants nonetheless described the provision of care to dying patients as an essential obligation of justice. A physician who had experience as a policy-maker described it thus: "...patients who simply need decent care for dying you need, you are obliged to calculate and provide resources to accommodate those patients...." (P14). Given 
these commitments, participants suggested that humanitarian health professionals should make provisions to ensure that such care is possible. For example, another physician policy-maker recommended that some healthcare resources should be dedicated to address the suffering of dying patients even during triage situations, including reserving pain medication for these patients and:

to keep some resource even some part of the, of the staff...to pay attention and to provide this basic care to people who will not be receiving...life-saving treatment: they will probably die, they may die, but at least they should die...in a respectful way, in a dignified way, and as much as possible without too much pain and with the presence of somebody. (P10)

Several participants expressed that it is important not to extrapolate from the most acute situations of urgency as a rationale for not addressing suffering or promoting dignity for patients in other humanitarian settings. As the acuity of an emergency decreases, a physician noted that the rationale to limit healthcare to primarily lifesaving efforts, with limited attention available to respond to other needs, "doesn't stay true" (P18). Moreover, a distinction was drawn between basic care that attends to suffering and dignity and a more comprehensive version of palliative care, which some saw as "a luxury" (P2, P11) in acute humanitarian settings.

Fundamentally, participants highlighted what they saw as a false divide and the need for more integration of curative and palliative approaches. Addressing the possibility that the focus on lifesaving would not leave room for palliative care approaches, a participant thus called for humanitarians to reject a choice between palliative care and curative care. He expressed that humanitarians should provide lifesaving care and "simultaneously...provide essential, basic human care to [patients who will die]. And it's not one or the other. It's we need to combine both approaches, and this probably is a small revolution in the way we envisage our role in the field." (P10).

\section{Working within, and resisting, systemic constraints}

Participants' efforts to provide palliative care were circumscribed by systemic constraints inherent to humanitarian operations and to the wider context of global inequality in healthcare access. Participants identified the different ways in which they engaged with unfair systems, and the impact these different ways of engaging had on the care they provided patients, and on their own well-being as care providers. Participants emphasized that it was feasible to address many needs of dying patients in humanitarian settings. A physician who had worked in three situations of armed conflict stated that "... from a human compassion perspective, some things that people die of are painful and uncomfortable. And we have the tools to limit that discomfort and we should use them" (P23). Various features of humanitarian projects were identified as enabling such care, including strong partnerships with local organizations, having clear guidance and supportive leadership, and access to opioids and other needed resources. However, it was more common for systemic features and a range of barriers to constrain health professionals in their response to those who were dying or likely to die. For example, care options are often limited by lack of access to material and human resources. Participants described lack of access to pain medications, especially opiates, as well as equipment (e.g., diagnostics, ventilators) and supplies. Shortages of staff with skills and training in palliative care or the presence of staff with skeptical or contrary views (be they local or expatriate health professionals) were also highlighted as barriers. When coupled with a lack of clear palliative care organizational policy guidance and clinical guidelines, these obstacles were further reinforced. Other systemic features were also identified. Participants were concerned when they saw patterns of neglecting suffering. For example, a physician felt that this tendency reflected a "tyranny of low expectations" (P22) which she associated with a form of implicit racism and which resulted in humanitarian organizations responding inadequately to pain and suffering. Overall, participants stressed that these challenges can and should be addressed with sustained effort to improve access and the quality of palliative care available.

Participants framed many of these features as unfair and as resulting from and/or contributing to wider inequalities. They described circumstances as unjust at the global level, such as inequalities related to which nations bear the brunt of the global refugee crisis (relative to their wealth and influence), or whether a particular patient would have survived their injuries if they had occurred in the participant's higher resourced home country. While discussing a patient who died of an infected wound, a physician from a high-income country noted that "I think we found it challenging because...if we'd seen this guy pre-hospital anywhere in [home country], we would have been able to deal with lots of these issues quite effectively" (P17). Another physician described her distress "performing treatments that I knew I could do with less pain and better tolerability in a better setting, but was unable to do at that time" (P22).

Participants also discussed unfairness in particular circumstances, such as expressing frustration when encountering patients dying from conditions that could have been easily prevented with better access to basic healthcare, and unfairness when certain subgroups within the local population had less access to care. Several participants also identified inequalities or inequities across humanitarian projects. 
For example, a physician described how there was "an uneven supply of medications across" (P3) Ebola Treatment Centers, including morphine. Discussing the same situation, a nurse identified the source of these inequalities as different rules amongst the Ebola Treatment Centers funders and partnering organizations. She worked in a center where the rules of a partnering organization prohibited the use of morphine and expressed that, as a result, "there was a lot of frustration that things were really bad for the patients in our treatment centers, and unfairly so" (P21).

Participants responded in a variety of ways to systemic constraints and the inequalities and unfairness that they engendered. In some settings, participants felt they needed to make reasonable if difficult compromises due to the constraining nature of the circumstances. Working in an insecure and chaotic armed conflict setting where there were few health professionals, a physician reported reluctantly making the decision to not allow family to visit their dying loved ones in the hospital. The team was, however, able to provide pain management despite the limited number of healthcare staff:

These people may die without their family members around them, which is obviously not ideal. But in those cases, I do think that's a reasonable limit to take for security reasons, for resource reasons, for function of the hospital reasons. So, that would be a

compromise that's made, suboptimal staffing, perhaps, and suboptimal psychosocial care, but nevertheless, a basic minimum in terms of pain management. (P23)

Participants also described that they and their colleagues sometimes needed to adjust their perspective in humanitarian settings. A physician from North America expressed that expatriate health professionals need to accept "that we can't do there what we can do [in home country]" (P15). She also described how she had needed to learn to become more accepting of the decisions made by patients and their families. She reported that it was difficult for her to understand a mother's decision process:

we can't even conceive of it, we can't even sort out how she's making her decisions, if she's going to stay with that child [in the hospital] or she's going to go home and look after the other eight ones that don't have anybody looking after them because their Dad has already been killed in the war. (P15)

Humanitarian health professionals react to these difficulties in varied ways, sometimes going beyond adjusting perspectives, to losing perspective. A physician reported that the austere and difficult circumstances of humanitarian emergencies can lead expatriate health professionals to "turn people into 'other', turn off your emotions and just be like, 'hold them down and we'll do this"' (P22). She asserted that taking this perspective must be actively resisted; regardless of the circumstances in which people are living, they should be treated with respect and be provided care to relieve their suffering.

Stories of responsiveness and adaptation in the context of the West African Ebola epidemic, for example, highlight ways that teams became more adept at working within and pushing against constraints, including by challenging policies and innovating to better address needs of patients in a context of extremely high mortality rates. A participant described that his team "got a lot braver and a lot more bold with how we were treating people and giving them a lot more attention or a lot better care" (P11) as the Ebola outbreak progressed and they developed more knowledge and skill for managing infection control risks while providing better and more compassionate care to patients. In other settings, emergent technologies were identified as providing support to overcome obstacles to care. For example, telemedicine was identified by two participants as a means to access experts in palliative care in situations where the team lacked such expertise. In another context, a physician described how, even when opioids were not available, ultrasound-guided nerve blocks could be used to provide effective pain relief.

Advocacy was also described as an important positive response to obstacles and constraints. This might occur at multiple levels: within the team, in the organization, and internationally. A physician policy-maker expressed that humanitarians should "advocate...for palliative care in humanitarian crises to be a basic human right...It should be the norm. It should be a human right and the norm" (P1). Many participants suggested that humanitarians can advocate within their organization for better access to resources needed for improving both curative and palliative care. A physician expressed that these dual advocacy efforts go "hand-in-hand" (P3). Discussing the many burned patients for whom her team was unable to provide adequate pain medication, a physician expressed regret that she had not been more forceful in her advocacy efforts, saying that "If I had been a little bit more on the ball about it, I could have kicked up a bigger stink" and demanded morphine and ketamine be made available (P22). These various responses ultimately reflect the weight of responsibility and moral obligation participants experienced in how they responded to patients in their care who were dying.

\section{Bearing the weight of responsibility}

The narratives convey a profound weight of responsibility felt by the participants. In stories of palliative care "done well" in a humanitarian setting, this weight felt 
lifted or at least lighter on the shoulders of participants. Many participants could not think of a case where palliative care was done well, but amongst those who could, their experience was a source of deep satisfaction. Providing effective palliative care "...allows the healthcare workers to feel that they are contributing and they haven't failed" (P6). However, even when care was done well, these encounters could still haunt participants as morally and existentially significant. For example, a nurse who had worked in an Ebola Treatment Centre described "a little girl, I think about the age of nine, and who called me, 'Uncle can you hold my hand', and because I knew that we could sit down and talk to them, so - which I did, and once I held her hand, she died... and so, for - for many, many months, even when I came [home], I could still feel that touch...I could still feel hear that voice" (P20). This experience stayed with him, and he described it as one factor in his seeking psychological support after returning from his field mission.

Situations which participants characterized as care not done well were often associated with particularly heavy emotional strain. Some described feelings of having failed certain patients, and these situations gave rise to distress and feelings of guilt or regret. This response was particularly acute when participants felt that they were implicated in a situation that was profoundly and inescapably unjust. For example, a physician described how "I've literally watched hundreds of babies seize to death and it's just a terrible...But I didn't have a way of keeping them comfortable, and letting them die in a warm, comfortable place and that really haunts me" (P22). Feeling somehow complicit in what was occurring, she went on to say that "I don't believe in hell, but I kind of think there is a special place in hell for me." Especially difficult were circumstances when patients who were dying in pain were turned away from care, a situation which can be "devastating emotionally" (P10) for humanitarian workers: "...it goes against everything that you - as a healthcare worker, as a humanitarian, everything - to do that to a human being, you know they're not gonna make it and just put them aside, it was - terrible (P19)."

In addition to stories of not providing care to dying patients or of insufficiently addressing symptoms or dignity for dying patients, participants also reported distress about providing treatment that prolonged the suffering of a dying patient when the participant felt that care should have been focused on palliation but was not, due to security concerns, or at the insistence of the family or other healthcare professionals.

Participants described strategies that helped them carry the weight of responsibility. They emphasized the importance of sharing the weight with trusted colleagues, through discussion and collaboration within teams. Close team relationships that included shared plans for responding to the needs for palliation were described as important. A physician described how a shared plan allowed his team to feel "comfortable with whatever was going to happen" (P15). Others talked about redirecting their feelings of not having provided sufficient care to some patients into action aimed at helping other patients, including through advocacy.

In contrast, several participants described actively trying to forget certain troubling experiences. Organizational strategies including support and debriefing were also identified as valuable. A nurse described the lack of ongoing psychological support for health professionals, especially national staff, providing care in Ebola Treatment Centers as one of the "big fails" of his organization (P11). He also identified training prior to departure as an important component for helping people anticipate the challenges of facing suffering, dying, and death, and better preparing for them.

Several participants reported struggling with their experiences of providing or not providing care to dying patients in a humanitarian crisis, even after their return home. For example, a nurse who had responded to the Ebola outbreak stated that:

yes, it was heavy...[S]ome of the things I did, they didn't actually cause any problems while I was there, but when I came [home], I couldn't sleep. It affected my sleep, my eating, even going to walk. I couldn't have a shower for some time so it was heavy when I came back...I had to receive - I got support... psychotherapy, for I think up to 6 months or 8 months...(P20)

Another participant reported a similar pattern, stating that:

You think about them when you come [home]. You don't have time to process anything [in the field], because you - you're so overwhelmed by the situation, you do what you can in that moment, and you have to move on, because the next day could bring the exact same thing. So you can only process for your own mental health what's right in front of you. Until you come home, at least....and then you start to kind of - really think about what you did, or what you didn't do, and - sometimes there's a big -... discordance of what - your ideals, and what you actually did...they just aren't meeting up and it's a huge mental struggle then. (P19)

For these participants, the weight of responsibility did not lift after they returned to their home countries. They reported lingering impacts of these experiences of 
responding to the needs of patients who were dying or likely to die in humanitarian crises, or of being unable to respond to these needs in what they felt was the right way.

\section{Discussion}

Participants in our study described alleviating suffering, upholding dignity, and accompanying individuals who are dying or likely to die as obligations of humanitarian health professionals and humanitarian organizations. Not providing care to such individuals in humanitarian crises was described and experienced by the majority as ethically wrong. At the same time, seeking to provide palliative care for dying patients was challenging. Intentions to provide such care could be severely constrained by limited resources available in the field or at a particular moment in a crisis. The dominant ethic of prioritizing lifesaving in the face of limited resources reinforced limited preparedness for and allocation of healthcare resources toward those patients who were not expected to survive. An awareness of cultural differences in end-of-life practices, expectations, and norms (Gaudio et al. 2013; Gysels et al. 2011; Hajjar et al. 2015) added another layer of complexity to the matter for providers working as expatriates in crisis settings. We propose these scenarios and decisions came across as ethically troubling to participants because of the degree of suffering experienced by dying patients, but also because of the way these situations highlighted existing limits for health professionals responding in situations of humanitarian crisis.

Responding to the needs of dying patients in humanitarian crises is heavily freighted with ethical implications, especially given the possibility of discordance between humanitarians' values and what actions seem possible in a humanitarian crisis, a reality that De Waal (2010) has described as the tragedy of humanitarian action. These situations also intersect with ideas about what it means to be a humanitarian, the duties of health professionals, and even what it means to be a human being. Encounters with patients who are last in line within a triage system that prioritizes the rescue and protection of life are remembered with a sense of particular importance. For a few participants, deciding to reserve scarce healthcare resources for those patients who are expected to survive affirms their humanitarian identity and responsibility, as such decisions link to the weight of having to determine how to allocate scarce resources. For most, such choices left participants deeply troubled. Expressed as guilt, outrage, or distress, these feelings are the moral residue (Webster and Baylis 2000) of being involved in compromised care that grates against their sense of doing the "right" or "human" thing and potentially result in moral distress (Jameton 1993).
The moral worlds of humanitarian healthcare professionals of which we caught a glimpse through this study reflect and reaffirm the goals of humanitarian action to save lives, alleviate suffering, and maintain human dignity (Sphere Project 2011a). According to our participants, the reluctance to include palliative care in humanitarian healthcare is the result of the overarching focus on lifesaving and rescue in this context, a view which equates death as (always) a humanitarian failure. Recent commentators have pushed for acceptance that not all patients can be saved in humanitarian settings and that the failure lies in not taking steps to address suffering and dignity for those who will succumb to injury or disease in these settings (Smith and Aloudat 2017). Participants generally expressed hope that more could be done for dying patients in humanitarian crises, in particular by integrating curative and palliative approaches to care, while also acknowledging systemic and cultural challenges to doing so (Hunt et al, 2017). The second draft of the updated Sphere handbook endorses the need to address suffering and pain relief for all patients, including people who are expected to die, and advocates for integration of palliative and curative approaches (Sphere Project 2017).

Along with justice in access to care, compassion stands out as an underlying ethical commitment in the participants' narratives of caring for patients who are dying or likely to die. While it could be argued that all care is (or should be) compassionate, a number of actions were identified by participants as meaningful moments because of the way these brought a non-medical, relational communion with pain and recognition of shared humanity into the humanitarian palliative setting. These included touch, simple conversation, and shared prayers with patients in the moments prior to death. Fundamentally, participants appeared to identify with the universality of the human conditions of pain, suffering, and death, and felt it demanded an empathetic, holistic, and tangible response. It is in this recognition and response to the humanity of the other that compassion appears to connect to the upholding of dignity in participants' moral worlds. The concept of dignity is widely used in a range of fields, yet its definition remains contested. Indeed, some bioethics scholars have argued that it is replaceable by more precise concepts such as respect for persons and autonomy, even calling it a "useless concept" (Macklin 2003). Barclay (2018) has countered this view, drawing on scholarship from political philosophy, to suggest that the distinctive contribution of dignity is in emphasizing and embodying equal moral worth. This perspective appears consistent with our participants' use of the term, and their emphasis on dignified death, including dying patients not feeling abandoned or treated as less than human. This perspective reflects a relational quality of dignity. It is also resonant with the broader 
discussion of dignity in humanitarian action, where it is directly associated with acts of respect for persons affected by crises (Sphere Project 2011b), and with conceptions of Ubuntu in African ethical thought (Behrens 2013).

Behind the narratives of some participants was a concern with entanglement in situations of political and social injustice. In this sense, providing palliative care, "because there is nothing else to offer," is associated with questions about being entangled in the manufactured circumstances that precipitated suffering and death. It reflects a broader concern for aid workers who, adhering to the humanitarian principle of neutrality, are conscious that advocating against injustice could mean they lose access to the community and those who need care most (Terry 2002). Different forms of complicity in humanitarian action have been identified, and attention has been directed to distinguishing them from related ethical concepts (Lepora and Goodin 2013). Amongst our participants, several experienced feelings of being complicit on a more individual level. Participants described moments when they or their colleagues failed to do enough as the moments that continue to haunt them. For example, participants 3 and 5 expressed a deep and lingering remorse for patients who they felt were denied a dignified death, as a human, due to inaction on their part. They may have been unable to take a moment to speak with the patient, to hold their hand, or tell them what was happening. Feelings of having failed to adequately attend to patients with palliative needs in humanitarian contexts engender moral stress that turns into moral distress when the cases are compounded, and individuals feel they have compromised significant personal and professional values. Lingering effects of this sense of complicity remain with actors as moral residue which might, in turn, cause them to feel helpless, distrust their own actions, and, turned inward, lead to compassion fatigue and burn out (Horning et al. 2017).

The study findings also draw attention to the importance of training and preparation in the area of palliative care in humanitarian settings. To effectively respond to the needs of dying patients, humanitarian healthcare professionals require training and skills, as well as guidance on how to provide palliative care in humanitarian crisis settings. Our participants identified experiences with patients and families facing dying and death as deeply affecting. However, many described feeling ill equipped or unsupported to respond effectively to the needs of these patients, and the moral distress this created for them at the time, and often long after. This included several for whom their experiences impacted their mental and emotional well-being to an extent that may have jeopardized their ability to continue in humanitarian work.
For most participants, expressions of the ethical imperatives of responding to suffering and upholding dignity were almost always coupled with a recognition of the pragmatic need for organizational and operational inclusion for the response to be consistent and effective. Currently, there are several ongoing initiatives that are seeking to address gaps in training and guidance. For example, Médecins Sans Frontières has developed a pediatric palliative care guideline (Smith and Aloudat 2017) and Médecins Du Monde is implementing a pilot project on pediatric palliative care in the Democratic Republic of the Congo (see Médecins du Monde 2016). These are encouraging developments and move in directions proposed by participants who identified organizational efforts to build a space for inclusion of palliative care as essential for engaging the complex contextual issues authentically and consistently. The context of humanitarian crises created needs for triage and prioritizing care that were often unique. Further, there was recognition that organizational palliative care standards would require significant adaptation to local perspectives given the cultural specificities of the nature of suffering and death. Differences between local and expatriate providers' views on suffering or when and how to acknowledge treatment futility were frequently cited. It was also recognized that care for those facing death would need to include families and communities explicitly. Furthermore, different forms of humanitarian crises (e.g., conflict, sudden onset disaster, epidemic) will shape needs and possibilities for palliative care provision, and these differences should be accounted for in guidelines and training.

On a higher level, it was hoped that inclusion would also be reflected in efforts by the wider humanitarian community to advocate on issues such as access to essential palliative medicines especially opiates and the international and national regulatory and policy issues that arise. According to the World Health Organization, "only about $14 \%$ of people who need palliative care currently receive it" (WHO 2018). Despite global statements that palliative care is a human right (International Children's Palliative Care Network 2008, WHO 2018) and a core component of universal health coverage (WHO 2018), access to sufficient pain relief is deplorably low in LMICs, especially amongst children (Knaul et al. 2018). This background situation directly affects access to pain management in humanitarian crises in LMICs, especially where law or policy limit or prevent the importation of opioids. Humanitarian actors have expressed a commitment to advocate (Nickerson and Attaran 2012) and rally international organizations, governments, policy-makers, and healthcare providers to take the "necessary steps to ensure that all patients in need have access to" essential medicines for palliative care (De Lima et al. 2007). It was 
felt that advocacy by humanitarian providers would further the recognition and inclusion of palliative care in national and local health systems globally. Concerns were raised about introducing care that could not be sustained once humanitarian response has ended, but this was offset with the potential opportunity for capacity building and health systems strengthening.

In response to their experiences in humanitarian care settings, many of our participants were led to advocate at different levels for the explicit inclusion of palliative care in humanitarian response. At the same time, it is crucial to ensure that palliative care is not seen as a replacement for curative care where it is possible to provide it (Smith and Aloudat 2017).

\section{Scope and limitations of the study}

This paper focuses on the experiences of expatriate health professionals responding to the needs of patients who are dying or likely to die in a humanitarian crisis. This is an important perspective, but still a limited angle of view. Investigating how patients, their families, and local communities and health professionals view and experience these situations is essential for better understanding what is at stake and for whom. Our larger research project involves in-depth field research in humanitarian settings, including perspectives from patients and their families. These inquiries will provide additional vantage points for understanding this topic. Several limitations are relevant to the analysis presented here. Our purposive sampling strategy was only partially successful. Most of the participants were Europeans or North Americans who primarily worked with the largest of the international NGOs. This does not reflect the wide range of nationalities of expatriate humanitarian professionals, or the spectrum of humanitarian organizations, and has undoubtedly shaped the range of experiences and ethical outlooks of the participants.

\section{Conclusion}

Death and dying are inescapable in humanitarian crises. Increased attention is being directed toward questions related to why it is important for humanitarian organizations to respond compassionately and in a just manner to the needs of these patients, and how they ought to plan for, implement, and assess these efforts. The study reported here provides important insight into the moral experiences of humanitarian health professionals who encounter such patients and highlights some important aspects of what is at stake in these situations. Their perspectives speak to both the essential importance and complexities of contextually appropriate palliative care. We hope that it will also encourage and support further dialogue in the humanitarian sector on this topic. It is crucial that humanitarian healthcare professionals are prepared, supported, and resourced in ways that enable them to attend to the suffering and uphold the dignity of some of their most vulnerable patients: individuals who are dying or likely to die in humanitarian crises.

\section{Endnote}

${ }^{1}$ At the time of writing, a second draft of the revision was available online (Sphere Project 2017).

\section{Abbreviations \\ LMICs: Low- and medium-income countries; NGO: Non-governmental organization; WHO: World Health Organization}

\section{Acknowledgements}

We are grateful to the study participants for sharing their experiences with us, to Rachel Yantzi for her assistance with formatting the manuscript, and to the other members of our research team, Laurie Elit, Lynda Redwood-Campbell, Olive Wahoush, Corinne Schuster-Wallace, Erynn Monette, Madeline McDonald, Ross Upshur, and Jhalok Ronjan Talukdar, for their contributions to our broader research study.

\section{Funding}

The research presented in this article was supported by a grant from Elrha's Research for Health in Humanitarian Crises programme (Project \#19775: Aid when there is "nothing left to offer": A study of ethics and palliative care during international humanitarian action). The Research for Health in Humanitarian Crises ( $\mathrm{R} 2 \mathrm{HC}$ ) programme aims to improve health outcomes by strengthening the evidence base for public health interventions in humanitarian crises. Visit www.elrha.org/work/ $\mathrm{r} 2 \mathrm{hc}$ for more information. The $\mathrm{R} 2 \mathrm{HC}$ programme is funded equally by the Wellcome Trust and DFID, with Elrha overseeing the programme's execution and management. Matthew Hunt is supported by a Research Scholar Award from the Fonds de Recherche du Quebec-Santé, and Lisa Schwartz is supported by the Arnold L Johnson Chair in Health Care Ethics.

\section{Authors' contributions}

$\mathrm{MH}, \mathrm{AC}$, and $\mathrm{KB}$ developed the initial idea for this manuscript. $\mathrm{MH}$ wrote the first draft, and all authors made substantial contributions as the paper was revised. SdL and EN conducted interviews with participants. GK and AC conducted initial coding of interview transcripts. All authors read the interview transcripts and participated in the data analysis. All authors approved the final version of the manuscript.

\section{Author's information}

Matthew Hunt is an associate professor at the School of Physical and Occupational Therapy of McGill University and an associate member of the Biomedical Ethics Unit. He conducts ethics research in the areas of global health and rehabilitation and co-leads the Humanitarian Health Ethics Research Group (humanitarianhealthethics.net).

Ani Chénier is an anthropologist whose work explores the ways mortuary and commemorative material culture enact and transform social imaginaries. She is a research coordinator with the Humanitarian Health Ethics Research Group at McMaster University.

Kevin Bezanson is a palliative care consultant for the Northwestern Ontario region and based in Thunder Bay, Ontario, Canada, with clinical, research, and program development experience mainly in Malawi and Ethiopia.

Elysée Nouvet is a medical anthropologist and an Assistant Professor in the School of Health Studies (Global Health) at Western University in London, Ontario. Her work focuses on lived experiences of trans-national aid and care. She is a co-lead of the Humanitarian Health Ethics Research Group.

Carrie Bernard is a family physician and palliative lead for the Queen Square Family Health Team in Brampton, Ontario. She is the Associate Program Director of the Postgraduate Family Medicine program at the University of Toronto and a member of the Humanitarian Health Ethics Research Group. Sonya de Laat is a scholar of histories of humanitarian photography. Current projects include photographs of refugees from the First World War, the visual archives of the Canadian International Development Agency, and projects on photo-based oral histories of humanitarian action. Gautham Krishnaraj is a research assistant with the Humanitarian Health Ethics Research Group at McMaster University. He is currently deployed as an Aga 
Khan Foundation Canada International Youth Fellow, supporting the health and education initiatives of the Madrasa Early Childhood Program—Kenya. Lisa Schwartz is a professor in the Department of Health Research Methods and Impact (HEI) at McMaster University and an associate member of the Department of Philosophy. She is the Arnold L Johnson Chair in Health Care Ethics and is a co-lead of the Humanitarian Health Ethics Research Group. Lisa is also a member of the Médecins Sans Frontières Ethics Review Board.

\section{Competing interests}

The authors declare that they have no competing interests.

\section{Publisher's Note}

Springer Nature remains neutral with regard to jurisdictional claims in published maps and institutional affiliations.

\section{Author details \\ ${ }^{1}$ School of Physical and Occupational Therapy, McGill University, 845 Sherbrooke Street West, Montreal, Quebec, Canada. ${ }^{2}$ Centre for Interdisciplinary Research on Rehabilitation, Montreal, Quebec, Canada. ${ }^{3}$ Humanitarian Health Ethics Research Group, McMaster University, 1280 Main Street West, Hamilton, Ontario, Canada. ${ }^{4}$ Northern Ontario School of Medicine, Lakehead and Laurentian Universities, Thunder Bay Regional Health Sciences Centre, 980 Oliver Road, Thunder Bay, Ontario, Canada. ${ }^{5}$ School of Health Studies, Western University, 1151 Richmond Street, London, Ontario, Canada. 'Department of Community and Family Medicine, University of Toronto, Toronto, Canada. ${ }^{7}$ Department of Family Medicine, McMaster University, Hamilton, Canada. ${ }^{8}$ Department of Health Research Methods \& Impact, McMaster University, 1280 Main Street West, Hamilton, Ontario, Canada.}

Received: 10 April 2018 Accepted: 27 June 2018

Published online: 03 September 2018

\section{References}

Barclay L (2018) Dignitarian medical ethics. J Med Ethics 44(1):62-67. https://doi. org/10.1136/medethics-2017-104467

Behrens KG (2013) Towards an indigenous African bioethics. S Afr J Bioeth Law 6(1):32-35

De Lima L, Krakauer EL, Lorenz K, Praill D, MacDonald N, Doyle D (2007) Ensuring palliative medicine availability: the development of the IAHPC list of essential medicines for palliative care. J Pain Symptom Manag 33(5):521-526

De Waal A (2010) The humanitarians' tragedy: escapable and inescapable cruelties. Disasters 34(s2):s130-s137. https://doi.org/10.1111/j.1467-7717.2010. 01149.x

Elrha (2017) Take part in the palliative care in humanitarian action survey now. http://www.elrha.org/news/take-part-palliative-care-humanitarian-actionsurvey-now/. Accessed 13 Mar 2018

Gaudio FD, Hichenberg S, Eisenberg M, Kerr E, Zaider TI, Kissane DW (2013) Latino values in the context of palliative care: illustrative cases from the family focused grief therapy trial. Am J Hosp Palliat Care 30(3):271-278

Giannou C, Baldan M (2009) War surgery: working with limited resources in armed conflict and other situations of violence, vol 1 Available via https:// www.icrc.org/en/publication/0973-war-surgery-working-limited-resourcesarmed-conflict-and-other-situations-violence. Accessed 20 June 2018

Gysels M, Pell C, Straus L, Pool R (2011) End of life care in sub-Saharan Africa: a systematic review of the qualitative literature. BMC Palliat Care 10(1):6

Hajjar RR, Charalambous HA, Baider L, Silbermann M (2015) International palliative care: Middle East experience as a model for global palliative care. Clin Geriatr Med 31(2):281-294

Horning J, Schwartz L, Hunt M, Williams-Jones B (2017) "If you let it get to you...": moral distress, ego-depletion, and mental health among military health care providers in deployed service. In: Messelken D, Winkler D (eds) Ethical challenges for military health care personnel: dealing with epidemics. Routledge, London, pp 71-91

Humanitarian Health Ethics Research Group (2018) Palliative care in humanitarian response. https://humanitarianhealthethics.net/home/research/hhe-researchstudies/pall-iphc/. Accessed 13 Mar 2018

Hunt M, Bezanson K, Bernard C (2017) Making space for palliative care in humanitarian action: Reflections on obstacles to the integration of palliative care approaches in humanitarian healthcare. Elrha. http://www.elrha.org/ r2hc-blog/making-space-palliative-care-humanitarian-action-reflections- obstacles-integration-palliative-care-approaches-humanitarian-healthcare. Accessed 13 Mar 2018

Hunt MR, Carnevale FA (2011) Moral experience: a framework for bioethics research. J Med Ethics 37(11):658-662

International Children's Palliative Care Network (2008) The ICPCN charter of rights for life limited and life threatened children http://www.icpen.org/icpcncharter/. Accessed 22 Mar 2018

Jameton A (1993) Dilemmas of moral distress: moral responsibility and nursing practice. AWHONNS Clin Issues Perinat Womens Health Nurs 4(4):542-551

Kleinman A (1999) Moral experience and ethical reflection: can ethnography reconcile them? A quandary for "the new bioethics". Daedalus 128(4):69-97

Knaul FM, Farmer PE, Krakaeur EL, De Lima L, Bhadelia A, Jiang Kwete X, ArreolaOrnelas H, Gómez-Dantés O, Rodriguez NM, Alleyne GAO, Connor SR, Hunter DJ, Lohman D, Radbruch L, del Rocío Sáenz Madrigal M, Atun R, Foley KM, Frenk J, Jamison DT, Rajagopal MR, on behalf of the Lancet Commission on Palliative Care and Pain Relief Study Group (2018) Alleviating the access abyss in palliative care and pain relief-an imperative of universal health coverage: the Lancet Commission report. Lancet 391(10128):1391-1454

Lamontagne F, Fowler RA, Adhikari NK, Murthy S, Brett-Major DM, Jacobs M et al (2018) Evidence-based guidelines for supportive care of patients with Ebola virus disease. Lancet 391(10121):700-708

Lepora C, Goodin RE (2013) On complicity and compromise. Oxford University Press, Oxford

Lincoln YS, Lynham SA, Guba EG (2011) Paradigmatic controversies, contradictions, and emerging confluences, revisited. In: Denzin NK, Lincoln YS (eds) The Sage handbook of qualitative research, 4th edn. Sage, Los Angeles, pp 97-128

Macklin R (2003) Dignity is a useless concept. BMJ 237:1419. https://doi.org/10. 1136/bmj.327.7429.1419

Marston J, De Lima L, Powell RA (2015) Palliative care in complex humanitarian crisis responses. Lancet 386(10007):1940

Médecins Du Monde (2016) Soins palliatifs pédiatriques: Quand guérir n'est plus possible, tout n'est pas terminé. https://medecinsdumonde.ch/activites/spp/ le-projet/. Accessed 13 Mar 2018

Nickerson JW, Attaran A (2012) The inadequate treatment of pain: collateral damage from the war on drugs. PLoS Med 9(1):e1001153

Nouvet E, Sivaram M, Bezanson K, Krishnaraj G, Hunt M, de Laat S, Sanger S, Banfield L, Escobio Rodriguez PF, Schwartz LJ (2018) Palliative care in humanitarian crises: a review of the literature. Int J Humanitarian Action 3(5). doi: https://doi.org/10.1186/s41018-018-0033-8

Powell RA, Schwartz L, Nouvet E et al (2017) Palliative care in humanitarian crises: always something to offer. Lancet 389:1498-1499. https://doi.org/10.1016/ S0140-6736(17)30978-9

Schneider M, Pautex S, Chappuis F (2017) What do humanitarian emergency organizations do about palliative care? A systematic review. Med Confl Surviv 33(4):263-272. https://doi.org/10.1080/13623699.2017.1409167

Smith J, Aloudat T (2017) Palliative care in humanitarian medicine. Palliat Med 31: 99-101. https://doi.org/10.1177/0269216316686258

Sphere Project (2011a) Glossary: humanitarian action. http://www.sphereproject. org/handbook/glossary/?|=H. Accessed 13 Mar 2018

Sphere Project (2011b) Humanitarian charter. http://www.spherehandbook.org/ en/the-humanitarian-charter/. Accessed 13 Mar 2018

Sphere Project (2017) Draft 2 of the Sphere Handbook now ready for review and feedback. http://www.sphereproject.org/handbook/revision-spherehandbook/draft-ready-for-feedback/. Accessed 19 Mar 2018

Terry F (2002) Condemned to repeat? The paradox of humanitarian action. Cornell University Press, Ithaca

Thorne S (2016) Interpretive description: qualitative research for applied practice, vol 2. Routledge, New York

Thorne S, Kirkham SR, O'Flynn-Magee K (2004) The analytic challenge in interpretive description. Int J Qual Methods 3(1):1-11

Webster GC, Baylis FE (2000) Moral residue. In: Rubin SB, Zoloth L (eds) Margin of error: the ethics of mistakes in the practice of medicine. University Publishing Group, Hagerstown, pp 217-230

WHO (2018) WHO media centre factsheet on palliative care. World Health Organization. http://www.who.int/mediacentre/factsheets/fs402/en/. Accessed 20 June 2018 